\title{
El neokantismo heideggeriano en las tensiones de la filosofía trascendental
}

\author{
The Heideggerian Neokantianism in the Tensions of the \\ Transcendental Philosophy
}

\author{
ANDRÉS CRELIER* \\ (Universidad Nacional de Mar de la Plata - CONICET)
}

\begin{abstract}
Resumen: El artículo sostiene que Heidegger en los años veinte del pasado siglo puede verse como un continuador de la filosofía trascendental kantiana. Sostiene que ambos proponen un programa crítico que busca romper con la tradición metafísica, e investigan por ello lo sintético apriori en las condiciones de la experiencia (Kant) o en la facticidad (Heidegger). En ambos se advierten las tensiones propias de la filosofía trascendental relativas a la constitución del mundo, la necesidad de postular un sujeto y la auto-reflexión. Se concluye que, en el caso de Heidegger, la renuncia a pensar en la universalidad de la factidad lo conduce a aporías ausentes en Kant, para quien la racionalidad no está sometida al tiempo.
\end{abstract}

Palabras Clave: Heidegger, Kant, filosofía trascendental, facticidad

\begin{abstract}
The paper claims that Heidegger in the 1920 s can be seen as a continuator of the Kantian transcendental philosophy, since both try to overcome metaphysics by inquiring into the apriori - the conditions of experience in Kant, facticity in Heidegger. Furthermore, both philosophers evince the tensions of the transcendental philosophy related to the world constitution, the need of a subject and selfreflection. Since Heidegger renounces to admit the universality of facticity, he is caught in aporias that do not beset the Kantian project, which puts forth an atemporal rationality.
\end{abstract}

Keywords: Heidegger, Kant, transcendental philosophy, facticity

El hecho es que cada escritor crea sus precursores. Su labor modifica nuestra concepción del pasado, como ha de modificar el futuro.

BORGES, “Kafka y sus precursores” (Otras Inquisiciones)

\footnotetext{
Este artículo es una reelaboración de mi trabajo "La hermenéutica de la facticidad en la tensión de la filosofía trascendental", presentado y discutido en el I Coloquio de Hermenéutica "Perspectivas de la hermenéutica contemporánea: discurso, técnica y praxis” (Mar del Plata, Argentina, 2008). Para esto resultó esencial la lectura, los comentarios críticos y los aportes de Leandro Catoggio y Leticia Basso.
} 


\section{Introducción}

La posición de Heidegger con respecto a Kant puede ser objeto -y lo ha sido- de una multiplicidad de lecturas incompatibles entre sí. En tanto se aspire a señalar una continuidad o una ruptura entre ambas filosofías, debe ya tomarse una primera “decisión” interpretativa, y el abanico de lecturas que se abrirá a partir de allí estará determinado, a su vez, por el modo en que se interprete dicho primer paso. En este trabajo voy a defender una posición "continuista" y, dentro de ella, voy a oponerme en algunas cuestiones centrales de la visión -también "continuista"- de Cristina Lafont, que de hecho me servirá como punto de partida para presentar mis tesis, referidas principalmente por cuestiones metodológicas y de espacio al Heidegger de los años veinte. En efecto, creo que es en principio allí donde se advierte una clara continuidad entre este autor y Kant, que puede utilizarse en todo caso como trasfondo para evaluar la relación del “segundo" Heidegger con el pensador de Königsberg.

Para justificar ante todo la defensa de una lectura continuista sirve recordar que una corriente de lectores de Heidegger ha seleccionado algunos aspectos de su obra, sin duda centrales, para oponerlo a Kant, como si ambos estuviesen embarcados en proyectos inconciliables. Según esta línea interpretativa, la "ontología fundamental” del Heidegger de los años veinte se encontraría en las antípodas de la filosofía trascendental kantiana. Mientras que esta última intentaría determinar la constitución activa de la objetividad por parte de un sujeto hipostasiado y sin mundo, cuyo carácter trascendental se opone a su inclusión en el ámbito empírico, Heidegger describiría la situación fáctica de ser en un mundo ya constituido. Mientras que la filosofía kantiana busca demostrar cuáles son las condiciones de posibilidad de la experiencia, en las cuales el sujeto juega el papel central, la hermenéutica heideggeriana describiría la situación fáctica del ser en el mundo, previa a toda distinción sujeto - objeto. Heidegger superaría de esta manera la metafísica de la subjetividad propia de la filosofía trascendental. ${ }^{1}$

Sin embargo, esta visión moldea a la filosofía crítica de un modo un tanto unilateral y a la medida del supuesto corte heideggeriano. Así, la ruptura cobra sentido pleno si se entiende que Heidegger se aparta radicalmente de un dualismo metafísico de sujeto y objeto que pone el acento en el primero de estos dos términos, es decir, si se postula como propio de la filosofía kantiana un sujeto trascendental sin mundo, que constituye y fundamenta toda objetividad desde una posición extrínseca. Ciertamente, la lectura heideggeriana de la filosofía moderna, y su pretendida superación de la epistemología, ha contribuido a forjar esa imagen de la posición kantiana, la cual sin dudas es más compleja.

Esta visión rupturista ha sido crecientemente cuestionada en base a los cursos dictados por Heidegger en la época de Ser y Tiempo, que fueron editados póstumamente. ${ }^{2}$ Allí se advierte que Heidegger no sólo no se encuentra en las antípodas del pensador de Königsberg sino que se propone expresamente y en el desarrollo concreto de su programa filosófico una continuación de la filosofía crítica. El problema es que Heidegger fuerza precisamente la lectura de la Crítica kantiana para afirmar a Kant como precursor. ${ }^{3}$ Tener en cuenta esto, e intentar una interpretación adecuada de esta “continuación” lleva a plantear una serie de complejas cuestiones que atañen a ambos pensadores.

Esta lectura se encuentra, por ejemplo, en la reconstrucción ya clásica de Danilo Cruz Vélez, 1970.

En sus de los '20 en Marburgo y Friburgo Heidegger se dedicó intensamente a retomar las problemáticas centrales de la Crítica de la Razón Pura con el fin de rescatar lo que había de original en ellas. Según Heidegger, el neokantismo había opacado la propuesta kantiana, entendiendo que ésta se restringía a una teoría de las ciencias. Cf. Prolegomena zur Geschichte des Zeitbegriffs (GA 20; curso del año 1925) Logik. Die Frage nach der Wahrheit (GA 21, 1925/26), Die Grundprobleme der Phänomenologie (GA 24, 1927) y Phänomenologische Interpretation von Kants Kritik der reinen Vernunft,(GA 25, 1927/28).

3 Como él mismo reconoce por ejemplo en el prefacio a la segunda edición de Kant y el problema de la metafísica, GA 3, p. XVII.

Studia Heideggeriana, Vol. I, 2020, $2^{\text {a }}$ ed. 
Es mérito de Cristina Lafont haber realizado una lectura continuista focalizándose en algunas de estas cuestiones, proponiendo tesis de base que hacen posible la comparación. Creo, sin embargo, que esta autora deja muy poco espacio a la problemática propiamente trascendental tal como ya estaba presente en Kant, o, dicho con algo más de precisión, deja poco espacio para pensar la filosofía trascendental como problemática. En este sentido, pasa por alto el hecho -no descuidado por el propio Heidegger- de que interpretar la posición de Heidegger con respecto a Kant exige también arriesgarse a realizar una relectura de la filosofía kantiana. No se trata, entonces, de presentar un Kant monolítico y discutir su presencia o ausencia en la filosofía heideggeriana sino de asumir el movimiento pendular al que conduce la tarea interpretativa, repensando problemas propios de la filosofía trascendental.

Ciertamente, como reza el epígrafe que elegí para este trabajo, el juego de develar influencias filosóficas suele esconder desfiguraciones o, al menos, reconfiguraciones previas. Aprovechando este hecho hermenéutico, mi tesis buscará ubicar a Kant y a Heidegger en un “campo interpretativo” lo más amplio posible, el cual, como sostendré, conforma una serie de aspectos típicos de la “filosofía trascendental”. Sostendré, por un lado, que la filosofía trascendental se caracteriza por una serie de ambigüedades, o, más precisamente, por una tensión entre maneras opuestas de entenderla, que atañen especialmente a la relación entre el sujeto y el mundo. En tal sentido, intentaré mostrar que la propia hermenéutica de la facticidad reedita una serie de dilemas propios del trascendentalismo. Pienso que se trata de tensiones que Heidegger quiere resolver pero que sin embargo lo atrapan, y, en suma, que la hermenéutica de la facticidad puede leerse como una nueva puesta en escena, en un lenguaje novedoso y sin dudas revolucionario, de las tensiones abiertas por Kant ciento cincuenta años antes.

\section{Alineando a Heidegger con Kant}

Para comparar a Heidegger -y más específicamente al "primer Heidegger”- con Kant y determinar en qué medida y en qué sentido el primero de estos autores transforma algunos supuestos básicos de la filosofía trascendental, es preciso ante todo "alinearlos" conceptualmente. Para decirlo en términos heideggerianos, la decisión previa que tomemos para alinearlos determinará el resultado de la investigación. Ciertamente, el intérprete debe justificar los presupuestos que utilice, y eso es lo que intentaré hacer en lo que sigue a partir de una crítica a la propuesta interpretativa de Lafont.

El paso inicial que da esta autora para ubicar a Heidegger en la problemática kantiana es considerarlo abocado al problema de los juicios sintéticos a priori. Ciertamente, este paso es problematizado por ella, pero a mi modo de ver constituye su base interpretativa por las siguientes razones: ${ }^{4} 1$ ) al formular el campo de problemas en términos claramente kantianos (recordemos que Kant resume la pregunta crítica en “cómo son posibles los juicios sintéticos a priori”) queda fuera de duda la vinculación entre ambos pensadores; 2) dado que luego del giro lingüístico el juicio se entiende naturalmente como lenguaje, este punto de partida se ubica con facilidad dentro del marco de lectura propuesto por Lafont sobre la apertura lingüística del mundo en Heidegger; 3) considerar que la problemática es la del juicio, sugiriendo que la preocupación central de Heidegger es un tipo de proposición, la sintética a priori, hace posible

4 El trabajo en donde está más claro su alineamiento de ambos autores en base a la problemática de los juicios sintéticos a priori es "Verdad y apertura de mundo. El problema de los juicios a priori tras el giro lingüístico" (Lafont, 2003, artículo basado en una conferencia en Berlín), cuyo título mismo resulta elocuente. En su libro Lenguaje y apertura del mundo. El giro lingüístico de la hermenéutica de Heidegger (Lafont, 1997) la continuidad de Heidegger con respecto a la filosofía trascendental es, a mi modo de ver, un tanto menos relevante. Finalmente, el capítulo titulado "Heidegger and the Synthetic A Priori” (Lafont, 2007), parece proponer una revisión del punto de partida aludido, el cual, sin embargo, me parece que se mantiene implícitamente en base a las razones que enumero. 
la contrastación con la tradición semanticista analítica (y permite confrontar a Heidegger con autores analíticos como Putnam); 4) finalmente, en el seno de este semanticismo, Lafont formula su tesis de que el significado determina la referencia, central para su interpretación de Heidegger.

Ahora bien, dado que esto violenta en gran medida las pretensiones ontológicas de Heidegger, Lafont sustituye -sin explicación previa- esta posición interpretativa por otra más neutra, según la cual tanto Kant como Heidegger están interesados en "lo sintético a priori”, que en este último autor adopta la forma de un "perfecto apriórico” (cf. Lafont, 1997, pp. 303 ss. y Lafont, 2007). Si bien esto último resulta más adecuado interpretativamente, Lafont pierde con ello las ventajas enumeradas anteriormente. Así, mi hipótesis de trabajo es que esta autora apoya su alineación de ambos autores, de manera a medias subrepticia, en este interés central por el juicio sintético a priori. Así, aprovecha las ventajas que esto tiene para la comparación entre Heidegger y Kant, por un lado, y la confrontación entre el primero y la tradición analítica semanticistas, por el otro, sin examinar todas sus facetas problemáticas, tan sólo ocultándola bajo la versión neutra.

Paradójicamente, Lafont acude a Heidegger para buscar apoyo textual, pero uno de los principales fragmentos citados revela lo que ella quiere ocultar:

Si radicalizamos el problema kantiano del conocimiento ontológico en el sentido de que no lo limitamos a la fundamentación ontológica de las ciencias positivas y si además no lo concebimos como problema del juicio, sino como la pregunta radical y fundamental por la posibilidad de la comprensión del ser en cuanto tal, entonces llegamos a la problemática filosófica fundamental de Ser y Tiempo. (GA 25, p. 426)

Heidegger advierte aquí explícitamente que la problemática de Ser y tiempo no es la del juicio. Por lo tanto, la inferencia de Lafont acerca de que la transformación heideggeriana de la filosofía trascendental, efectuada en Ser y Tiempo, "pretende superar el limitado alcance del conocimiento ontológico en la filosofía de Kant más que el modelo kantiano para su comprensión" (2003, p. 58; 2007, p. 105), o bien que se trata de una "ampliación material" (1997, p. 311), resulta cuestionable. Pues no se trata de ampliar el alcance de la filosofía kantiana sino de transformarla ontológicamente. Más aún, Heidegger no sólo transforma la problemática kantiana sino que “crea” a su precursor, señalando que Kant mismo estaba involucrado en una problemática eminentemente ontológica: "El conocimiento trascendental no investiga pues el ente mismo, sino la posibilidad de la comprensión previa del ser, lo que quiere decir, al mismo tiempo, la constitución ontológica del ser del ente” (Heidegger, NB, p. 25; GA 3, p. 16). Si bien el lenguaje kantiano es fuertemente gnoseológico, y también lo es el lenguaje empleado por Heidegger para realizar su interpretación, en donde habla por ejemplo de "conocimiento ontológico” (cf. GA 3, p. 13), la transformación ontológica resulta de todos modos enfatizada.

Pero veamos esto más de cerca, ¿cuál es la problemática kantiana del “juicio” y por qué Heidegger no la acepta como punto de partida? En términos generales, este concepto ha dado lugar a dos modelos interpretativos que tienen apoyo textual en la obra kantiana. Por un lado, el juicio es visto como una acción del sujeto en el contexto de una “psicología trascendental”. El entendimiento sintetiza las representaciones recibidas dando lugar a juicios y, por la misma acción, al conocimiento de objetos (A 79-80/B104-105). Esta problemática no puede ser la heideggeriana, ante todo porque Heidegger trata justamente de superar la filosofía del sujeto. Y aunque, como veremos, puede arriesgarse en algunos aspectos una equiparación del Dasein con un sujeto, no hay en Heidegger una "metafísica” de las facultades para explicar un cierto tipo de juicio, como sí hay en Kant.

Por otro lado, existe una vertiente interpretativa de la filosofía kantiana que pretende ignorar toda referencia a las facultades subjetivas para centrarse en los propios juicios, entendidos ahora como principios del conocimiento empírico o como aquellas condiciones que cualquier 
concepción de la experiencia debe incluir (cf. Strawson, 1975). ${ }^{5}$ Esta interpretación logicista del juicio, que le permite a Lafont contrastar a Heidegger con el semanticismo analítico del siglo $\mathrm{XX}$, no representa ningún núcleo de la filosofía heideggeriana al menos por dos razones: ${ }^{6} 1$ ) Esta filosofía está signada por un "giro ontológico" desde el cual pierde peso la pregunta por las condiciones de posibilidad de la experiencia; 2) El lenguaje -que "abre mundo"- no es entendido como "juicio” en ninguna posible acepción kantiana (no es acción de un sujeto ni una forma constituida por sujeto y predicado). ${ }^{7}$

Hasta aquí la crítica a Lafont. He pretendido con ella poner en evidencia las dificultades de alinear de manera unilateral a Heidegger con Kant y, en particular, de iniciar una interpretación continuista en base a una distorsión del planteo heideggeriano y una simplificación del kantiano. Sin embargo, quisiera resaltar ahora los puntos en los que acuerdo con Lafont, aquellos acuerdos básicos que toda postura continuista debería admitir: 1) Ambos autores elaboran un determinado “apriorismo” y en particular un “apriorismo sintético”; 2) Este apriorismo tiene la forma de una cadena de condiciones, que en Kant tiene la forma de la oposición básica a priori / a posteriori, y en Heidegger de ontológico / óntico u originario / derivado.

Al profundizar el sentido de esta continuidad básica, y a diferencia de Lafont, en lo que sigue de este trabajo voy a alinear a Heidegger con Kant en base a una secuencia de tesis opuestas propias de la estructura paradojal de la filosofía trascendental.

\section{Heidegger como continuador de la tarea crítica: la facticidad como limitación auto- reflexiva}

Mi tesis continuista inicial, a diferencia de la de Lafont, no se centra en los juicios sintéticos a priori como núcleo conceptual común sino en que tanto Heidegger como Kant proponen un programa filosófico crítico en el sentido de la pretensión de romper con la tradición metafísica. Esta tarea crítica es la contracara de la asunción de la pregunta por "lo" sintético a priori, pues en ambos casos la ampliación epistemológica o hermenéutica del contenido filosófico se realiza en base a un rechazo a ubicar dicho contenido "más allá” de la experiencia -en el caso de Kanto de la facticidad -en el caso de Heidegger-. Lo sintético a priori ya no está "más allá” de la experiencia o de los entes sino más acá de ella y de los entes que comparecen en el mundo. Este “giro copernicano” y sus implicancias críticas, en las que pondré ahora el acento, están pues en la base de ambos proyectos (independientemente del lugar que ocupe un sujeto en este giro y del carácter de dicho sujeto).

\footnotetext{
Beiser explica los rasgos generales de esta lectura logicista en Beiser, 2002, pp.169-172.

Dejo de lado las razones filosófico-históricas como el rechazo heideggeriano del neokantismo, el cual se acerca a una interpretación "logicista” de la filosofía kantiana (mientras que Heidegger mismo recurre en Kant y el problema de la metafísica a la primera edición de la CRP, el locus clásicamente rechazado por la vertiente interpretativa a la que estoy haciendo referencia.)

7 Lafont le da un contenido a su concepción del lenguaje en Heidegger con su tesis de que en este autor el significado determina la referencia, desarrollando así su programa comparativo en base a una previa transformación de Heidegger en un pensador “semanticista” (la “apertura lingüística del mundo” tiene este carácter, cf. Lafont, 1997). Además de las críticas que ya he realizado a esta transformación, se suma una consecuencia importante que ni Heidegger ni Kant, a mi modo de ver, aceptarían. La tesis de que el significado determina la referencia resulta cercana a un idealismo que excluye toda materia dada del conocimiento o de la realidad (la cosa en sí, la multiplicidad dispersa o los entes a los que accedemos). En efecto, hablar de "referencia", incluso de "referencia posible", alude inevitablemente al objeto dado. En cambio, el "idealismo trascendental" kantiano es puramente formal, y tiene como contracara un "realismo empírico” según el cual los objetos no son producidos por el sujeto en sus aspectos materiales. En términos semanticistas, la referencia no es determinada completamente por el significado. De modo análogo, Heidegger insiste en que lo ontológico determina lo óntico en su modalidad, no en todos los aspectos de su contenido.
} 
En este apartado me ocuparé del sentido de este giro en Heidegger, dado que la filosofía kantiana es en este punto más conocida. Al igual que Kant, el Heidegger de los años veinte pone límites a la especulación propia de la tradición occidental y propone un "nuevo comienzo", cuya radicalidad se plasma en la exigencia de que la investigación filosófica tenga en cuenta de entrada la situación actual en la cual se realiza. La expresión "hermenéutica de la facticidad" es pues un genitivo subjetivo, pues es la propia facticidad la que se interpreta a sí misma (Gadamer, 2002, p. 282).

El poner límites tiene pues la forma de una tarea auto-referencial o auto-reflexiva. Ciertamente, no se trata de una reflexión en el sentido kantiano, entendida como el intento por determinar a qué facultad subjetiva pertenece determinado conocimiento a priori encarnado en un juicio. Esto supone una noción de sujeto que permite la disecación de sus facultades cognoscitivas, es decir, una metafísica que Heidegger busca dejar atrás (aunque, como veremos, también puede pensarse que ya Kant estaba embarcado en dicha superación). En todo caso, la idea moderna de reflexión, tal como aparece ya en Locke, tiene un trasfondo óptico que se adecúa a la hermenéutica heideggeriana, pues alude al recorrido de la luz reflejada en un espejo. Así, mediante reflexión aludiré a esta vuelta de la mirada hacia sí, que Heidegger considera como el "autoconocimiento bien entendido" (SZ, p. 170) imprescindible para elaborar los momentos estructurales del ser-en-el-mundo. Teniendo en cuenta esto, no me parece entonces forzado aplicar la noción de "reflexión” también a Heidegger.

En el Informe Natorp se afirma que el contenido de una interpretación, su tema u objeto, "sólo se logra mostrar directa y adecuadamente cuando la correspondiente situación hermenéutica de la que depende toda interpretación resulta accesible de una manera suficientemente clara” (Heidegger, NB, pp. 29-30 y SZ, p. 252). Como se advierte, tema y situación coinciden en un proceso interpretativo concebido reflexivamente. En general, la remisión al aquí y ahora concreto de la interpretación define con simplicidad y justeza qué se entiende, en este contexto, por lo "fáctico". Sin embargo, no debe leerse en este concepto un factum brutum, es decir, un conjunto de entes o hechos del mundo. Por el contrario, puesto que toda interpretación depende de la facticidad, ésta es el horizonte mismo o la condición de posibilidad de toda objetividad, dicho en términos claramente trascendentales.

Una vez planteada esta exigencia metódica para toda interpretación, queda claro que la filosofía misma debe entenderse como "modalidad de la vida fáctica” (Heidegger, NB, p. 34). Sólo que, aunque derivada de lo cotidiano, esta disciplina tiene la incorrecta pretensión de haberse desprendido del propio punto de vista, especialmente desde la modernidad. Volviendo las cosas a su lugar mediante un "giro hermenéutico", el "objeto" de la investigación, o más bien su tema, resulta ser la propia existencia humana, el "Dasein" humano o la "vida fáctica" (NB, p. 31). ${ }^{8}$ No se rechaza con ello otros tipos de investigación, abocados a estudiar "regiones de lo que es”, sino que se muestra la necesidad de no olvidar el punto de partida fáctico de toda investigación, incluso de aquella que no tematiza la facticidad. Se trata de una tarea explicitatoria, reconstructiva o "fenomenológica”, cuyo fin es que aquello mostrado se muestre desde sí mismo (SZ, pp. 50 ss.). Como consecuencia, la dirección de la investigación filosófica es para Heidegger una "aprehensión explícita de una actividad fundamental de la vida fáctica”. La perspectiva es inmanente y auto-reflexiva en el sentido indicado, dado que la tematización de la vida fáctica es necesariamente interna.

Así como sucede con varios cursos de los años veinte, el Informe Natorp esboza ya con cierto detalle el proyecto de Ser y tiempo. Esta obra utiliza de modo casi excluyente la expresión central "Dasein” para sustituir un léxico todavía en proceso de fijación, que incluye “vida fáctica”, facticidad, “Dasein humano” y "Dasein”, entre otros conceptos. 
En Ser y tiempo es la expresión “Dasein” la que se encarga de señalar la facticidad en tanto estructura ontológica del ser o estar en el mundo. ${ }^{9}$ Previa a toda noción moderna de conciencia, hombre, sujeto de conocimiento y ciencia teorética objetiva, el Dasein aspira a conceptualizar la irrebasabilidad del punto de vista, o más bien, la necesidad de asumir el propio punto de vista irrebasable, el del “allí” mío “en cada caso” todavía indiferenciado (SZ, p. 67). El Dasein carga, entonces, con las notas del concepto de facticidad, dado que se define justamente por la autoreferencia que le es propia o le compete de manera constitutiva; se trata -recordemos- de un ente al que "le va” en su ser este mismo ser. Esta apertura para sí mismo es una posibilidad constitutiva de volverse hacia sí mismo, que para Heidegger toma también la forma de un “anticiparse a sí mismo” (SZ, pp. 35, 113, 213). Podemos decir que el Dasein se caracteriza por ser capaz de asumir la irrebasabilidad de su situación fáctica, de su horizonte constituido por el aquí y ahora.

La "pregunta por el ser” es entendida como la "radicalización de una esencial tendencia de ser que pertenece al Dasein mismo” (SZ, p. 37). Se trata de un preguntar por lo irrebasable, ya que todo ente es de alguna manera. Al margen de que se pueda elaborar una tal pregunta de manera adecuada, resulta claro que cualquier pregunta que interrogue por el ser estará afectada por aquello que interroga. Deberá ser, entonces, radicalmente “auto-reflexiva” en el sentido indicado, algo que Heidegger advierte cuando examina la estructura formal de este tipo de indagación: "elaborar la pregunta por el ser significa hacer que un ente -el que pregunta- se vuelva transparente en su ser” (SZ, § 2). La pregunta es entonces por "el modo de ser de un ente”, el Dasein -el “ahí” del ser-, y por ende el "ahí” donde se efectúa toda pregunta por el ser.

En suma, poner límites a la filosofía cobra la forma -al igual que para Kant- de una tarea reflexiva. Mientras que Kant la reflexión todavía está enmarcada en una actitud teórica contemplativa realizada por un sujeto trascendental (lo cual admite, como veremos, más de una interpretación), aquí se exige una auto-reflexión radical que supera la propia distinción entre sujeto y objeto. En todo caso, se trata de una radicalización del propio impulso trascendental de limitar la especulación metafísica, y de una profundización de la propia reflexión, que ahora debe ser una auto-reflexión sobre la facticidad.

\section{El mundo siempre ya constituido}

Si bien la tarea crítica representa como vimos un aspecto esencial de la reflexión trascendental, su remisión a la experiencia posible (Kant) o a la facticidad radical (Heidegger), conlleva una consecuencia teórica que tiende a anularla. Se trata de la imposibilidad de acceder a las condiciones de posibilidad (cognoscitivas u ontológicas) que la reflexión debería ser capaz de explicitar. En lo que sigue reconstruiré esta dificultad como uno de los dos polos de una tensión propia de la filosofía trascendental, tensión que atrapa a los dos autores estudiados.

Como se ha visto con claridad desde el idealismo alemán, la filosofía trascendental kantiana esconde una ambigüedad difícilmente superable y propicia una doble vertiente interpretativa. $\mathrm{O}$ bien la experiencia es algo "siempre ya" constituido, o bien, como veremos en el próximo apartado, es fruto de la actividad sintética por parte de un sujeto. La interpretación quizás más extendida es justamente esta última, dado que Kant propone claramente una serie de dualismos y luego intenta explicar cómo se relacionan los dos elementos en juego. La interacción entre un entendimiento activo y una sensibilidad pasiva explica el conocimiento empírico, pero da lugar

9 Como es sabido, las traducciones más recientes (no sólo al español) evitan traducir el término alemán “Dasein” “Ser-ahí”, en la traducción clásica de José Gaos- para no tergiversar este concepto identificándolo con una cosa del mundo o con el propio hombre. De esta manera, más que una abstracción obtenida a partir de un ente concreto como el hombre, el concepto de Dasein se obtiene mediante una auto-reflexión radicalizada sobre el aquí y ahora fáctico. Como resultado de la misma, se llega a la noción de que el Dasein no puede ser algo ahí. 
al problema de cómo es posible que dos elementos radicalmente heterogéneos -pensamiento e intuición- interactúen entre sí, problema que Kant intenta solucionar con su doctrina del esquematismo.

Según la doctrina kantiana de la síntesis, la actividad unificadora de un sujeto se ejercería sobre una materia dada. Pero como la experiencia es el fruto de esa síntesis, dicha materia es un postulado que sobrepasa los límites de toda experiencia posible. Asimismo, la acción sintetizante no puede ser entendida como una acción empírica, de manera que su naturaleza de “acto" se vuelve difícil de concebir. Así, tanto la materia a sintetizar como el sujeto que la sintetiza caen bajo las restricciones críticas iniciales.

Para evitar este tipo de dificultades, puede avalarse otra interpretación de la constitución empírica en Kant, que hace en cierto modo violencia al dualismo cognoscitivo kantiano (sensibilidad y entendimiento), pero también tiene apoyo en el pensador de Königsberg, quien limita todo conocimiento al ámbito de la experiencia posible, es decir aquel ámbito en donde puede darse una intuición empírica. La síntesis activa realizada por un sujeto a partir del material intuitivo puede entenderse como una capacidad subjetiva "siempre ya" y necesariamente realizada. Podemos reconstruirla, pero no podemos afirmar que ésta se realiza en una secuencia temporal (pues el tiempo es una forma pura de la subjetividad), de modo que la filosofía trascendental no podría entenderse como una teoría de la constitución a través de una serie de síntesis temporales.

Esto pone en duda la legitimidad de un conocimiento de las condiciones del conocimiento, las cuales se encuentran siempre ya unidas a lo condicionado, de manera que no es posible acceder a ellas sin exceder los límites del propio criticismo. Y, en todo caso, se dificulta la distinción en dos facultades y de dos fuentes heterogéneas que producirían lo que, de todos modos, ya se encuentra necesariamente constituido. Esta interpretación monista -enfatizada por discípulos de Kant como Reinhold y Fichte, por ejemplo- se encuentra ya en la célebre tesis de que las condiciones de posibilidad de la experiencia (lado subjetivo) son las mismas que las de los objetos de la experiencia (lado objetivo) (A 111). La experiencia, según esto, sería un todo ya organizado, cuyos elementos pueden a lo sumo disecarse analíticamente según el método “abstractivo” propio de la filosofía kantiana, pero que nunca pueden presentarse por separado. ${ }^{10}$

En esta misma línea de pensamiento puede ubicarse la concepción heideggeriana de que el mundo está ya constituido: el Dasein es ser-en-el-mundo. La facticidad puede entenderse como una alusión a que estamos arrojados en un mundo en el que las cosas tienen ya significado. El Dasein es un punto de vista de sentido (SZ, p.175). Cada vez que comprendemos algo determinado (sea en el marco de la teoría filosófica o de la comprensión cotidiana) es preciso haber comprendido ya en una situación determinada. Según esta tesis hermenéutica central, todo comprender se apoya necesariamente en una "pre-comprensión”, no puede haber comprensión “desde cero” o grado cero de la comprensión, es decir, un estado previo al sentido mundano.

De este modo, primero comprendemos y luego nos planteamos interrogantes sobre qué significa comprender (o hacemos teoría sobre el comprender). Para decirlo utilizando la dimensión temporal, lo primero es estar “arrojados” en un mundo con sentido y lo segundo es cualquier reflexión o investigación que pretenda explicarlo o mostrarlo conceptualmente: el “fundamento" sólo es accesible como sentido (Ibid.). Heidegger ofrece algunos ejemplos elocuentes: afirma que usualmente no oímos ruidos sino la motocicleta o el fuego, no oímos el sonido de las palabras sino aquellos que se nos quiere decir (SZ, p. 187). Podemos agregar el ejemplo de que nunca oímos sonidos o ruidos que luego identificamos como música, sino que

10 Kant insiste en esto. Afirma, por ejemplo, que la analítica es la descomposición (Zergliederung) de nuestro conocimiento a priori en los elementos del conocimiento puro del entendimiento (A 64/ B 89). O también que la lógica trascendental consiste en aislar (isolieren) el entendimiento para resaltar, en el conocimiento, la parte que tiene su origen en el entendimiento; lo mismo que la estética trascendental hacía con la sensibilidad. (A 62/B 87). 
oímos primero una melodía, un ritmo, etc., y sólo luego podemos volver artificialmente nuestra atención hacia los sonidos mismos para entenderlos como sonidos, o incluso para percatarnos de que la música está hecha de materia sonora.

La comprensión es una apertura al sentido (es decir, al horizonte del ser-en-el-mundo) previa a toda teoría, por lo que todo comprender particular resulta derivado. Y afirmar que el Dasein comprende equivale a afirmar que el mundo comprendido posee significado. Con palabras de Heidegger: “el mundo sale al encuentro con el carácter de la significatividad”, la cual es incluso una condición de posibilidad del lenguaje (SZ, pp. 114, 166 ss.; NB, p. 36). Así, lejos de ser el juicio o el significado proposicional lo que "abre mundo", existe una "significatividad originaria” que no es todavía lenguaje -al menos no es proposición, ni enunciado ni palabra, etc.- sino condición de posibilidad del mismo.

La filosofía elabora un conocimiento de una estructura previa ya significativa, surgiendo naturalmente el reproche de circularidad. Como se sabe, Heidegger es consciente de esta objeción, a la que califica de formal y estéril en la investigación de los principios (SZ, pp. 31 y 176). El comprender investigado por Heidegger atañe, en sus palabras, a las "condiciones fundamentales de toda interpretación”. Para detectarlas, resulta imperioso no salir del círculo, sino "entrar en él de forma correcta”, ya que él representa la "expresión de la estructura existencial de prioridad del Dasein mismo”, y si se logra abordar correctamente esta estructura circular, se obtendrá un conocimiento positivo más “originario”, que sea una auténtica “elaboración de esa estructura de prioridad a partir de las cosas mismas” (SZ, pp. 176 y 334).

\section{Las estructuras activas y la constitución del mundo}

Si en el apartado anterior Heidegger se ubicaba cómodamente, mientras que Kant era forzado a asumir algunas consecuencias de su propio criticismo, en lo que la situación se presenta en el sentido inverso. Al mundo siempre ya constituido se le opone ahora la concepción trascendentalista de una constitución activa del mundo. Siguiendo entonces la visión “tradicional” de la filosofía trascendental, forzaré en cierto modo ahora a Heidegger para ubicarlo en ella. Para ello pondré en evidencia el papel clave que en ambos autores tiene la búsqueda de aquello que, en la tradición trascendental, se expresa mediante el giro "condiciones de posibilidad”, subrayando a continuación el carácter de estructura activa que tienen dichas condiciones.

Resulta evidente que Kant considera posible acceder reflexivamente a las condiciones de la experiencia desligadas de lo condicionado y, más aún, que podemos considerarlas determinantes, al menos en aspectos empíricos formales. Esta tarea típicamente trascendental consistente en elaborar conceptualmente las “condiciones de posibilidad” -en Kant de la experiencia- también está presente en la hermenéutica de la facticidad heideggeriana, centrada, como Lafont ha visto, en la tarea de elaborar conceptualmente "lo a priori".

Ciertamente, y de acuerdo con su proyecto de una “ontología fundamental”, Heidegger no está interesado en sacar a la luz las condiciones del conocimiento empírico, pero tampoco cree que Kant lo haya estado. Según su peculiar interpretación, el conocimiento trascendental investiga "la posibilidad de la comprensión previa del ser" (GA 3, p. 25). De este modo, Heidegger se ve a sí mismo como un continuador de Kant y su metafísica de la finitud (SZ, p. 249). La exactitud de esta auto-comprensión es avalada por Gadamer, para quien Heidegger continúa aquí el proyecto husserliano y neokantiano de una fundamentación trascendental, aunque apunta a concretizar la conciencia trascendental en un Dasein fáctico. Lo importante, en todo caso, es que "el rechazo de una «conciencia en general» no significa la negación del $a$ priori”, el cual es ahora un a priori de la facticidad (Gadamer, 2002, pp. 114-115). La inicial remisión a un aquí y ahora en los que está necesariamente inmersa la propia investigación 
teórica termina descubriendo una estructura previa a cualquier experiencia de objetos, recuperándose con ello la diferencia kantiana entre lo trascendental y lo empírico (cf. Lafont, 1997, cap. 5, pp. 303 ss.). Tomando como referencia a Husserl, Heidegger reivindica al apriorismo como "método de toda filosofía científica que se comprenda a sí misma” (SZ, p. 75n).

La insistencia de Heidegger en aguzar la mirada fenomenológica se expresa principalmente en una serie de conceptos semánticamente ligados por el prefijo alemán "vor”, en español "pre” o "previo". ${ }^{11}$ En Ser y tiempo se asume plenamente el carácter estructural de las relaciones entre estos conceptos denominados genéricamente “vor”. Este horizonte estructural permite que las cosas sean de tal o cual modo, es formal -no tiene un contenido más allá de la experiencia-, es independiente de cualquier experiencia, y, finalmente, es condición del comprender, es decir, de la experiencia y del conocimiento en general. Así, esta "estructura de ser ya subyacente en cada caso” (SZ, p. 221) constituye una “condición ontológica de posibilidad” elaborada por la hermenéutica.

La “elaboración” consiste en volcar conceptualmente una serie de “existenciarios”, los cuales, de modo análogo a las categorías revelan determinaciones a priori del ente (SZ, pp. 60 y 70). Así como la analítica kantiana aísla y reconstruye una serie de categorías que son condición de posibilidad de la experiencia (en términos heideggerianos, se trata de determinar los caracteres ontológicos del ente que no es el Dasein), la analítica heideggeriana aísla y reconstruye la estructura de la propia facticidad, empezando por la estructura general de ser-enel-mundo. Siguiendo este paralelo, podemos afirmar que la facticidad se constituye activamente. En la "diferencia ontológica” existe un polo activo y otro pasivo, lo cual se advierte en que Heidegger utiliza términos como “determinar” para referirse a la relación entre las condiciones y lo condicionado.

Existe, puede objetarse, una diferencia sustancial entre Kant y Heidegger en este punto. Mientras que el primero centra la estructura categorial en un sujeto activo, el segundo supera toda distinción entre sujeto y objeto. Según esto, no sería posible pensar un polo activo -al modo de un sujeto- y sostener el paralelo que estoy proponiendo. Frente a esta objeción, creo que puede alegarse que la noción de "actividad” puede permanecer indeterminada y desligada de un sujeto. La historia de la filosofía post-kantiana nos enseña justamente que es posible concebir un idealismo kantiano ya no subjetivo sino "absoluto". ${ }^{12}$ Dicho brevemente y sin desarrollar, el papel activo puede ser desempeñado por ideas o estructuras, algo que ya está sugerido por el propio Kant y su concepción del sujeto, como veremos en el próximo apartado.

\section{Heidegger en la tensión de la filosofía trascendental}

Los dos apartados anteriores muestran el arco de tensiones que a mi juicio caracterizan a la filosofía trascendental y ubican a Heidegger dentro de este arco de dilemas. En esto se revela la continuidad con la filosofía kantiana, y no tanto en su propuesta de superación de la distinción del dualismo metafísico sujeto - objeto, algo ya intentado por el propio Kant, ni en la continuidad de una indagación acerca de cierto tipo de juicio, algo que he puesto en duda más arriba. Quisiera resumir ahora las principales ambigüedades en las que Heidegger se encuentra atrapado.

La primera ambigüedad concierne a la constitución del sentido mundo. Por un lado, el mundo está ya siempre y necesariamente constituido, pues no hay Dasein sin mundo ni al revés. Como vimos, también Kant limita todo conocimiento a la experiencia posible, la cual es un todo

11 Entre estos conceptos característicos de los años veinte se encuentran Vorsicht (ver previo) Vorgriff (manera de entender previa), Vorhabe (haber previo), Vorblick (mirada previa), entre otros: cf. SZ, pp. 174-175 y GA 63, pp. 79-80.

12 En este eje de lectura se central el libro de Beiser, 2002. 
organizado, y la tarea reflexiva consiste en aislar analíticamente los diversos elementos de esa totalidad. Por otro lado, sin embargo, el mundo se constituye activamente, algo que en Kant se entiende de modo más natural. Creo que, de un modo análogo, puede pensarse que en Heidegger existe una estructura ontológica constituyente: el Dasein es apertura de sentido, los entes comparecen determinados por el temple anímico, la praxis posee prioridad por sobre la teoría, lo ontológico “determina” lo óntico, etc. Heidegger sintetiza este dilema con su noción del Dasein como "proyecto arrojado”, es decir, el Dasein constituye activamente el sentido en tanto proyecto, pero, paradójicamente, está ya siempre en un mundo constituido, arrojado en él con la consiguiente extrañeza existencial que esto le provoca. Creo que esta condensación conceptual de la paradoja que opone la noción de un mundo ya constituido a una constitución activa del mismo no la resuelve, tan sólo la profundiza.

La segunda ambigüedad atañe a la presencia o ausencia de algo equivalente a un sujeto moderno. Por supuesto, lo primero que se dice es que el Dasein no es sujeto, que es algo previo y más “originario” que la distinción moderna entre sujeto y objeto. Esto tiene su equivalente en Kant, para quien el sujeto trascendental no es, ante todo, un sujeto empírico ni puede tener contenido más allá de la proposición “yo pienso”. Este sujeto o “apercepción trascendental” es una función "lógica” que da unidad a la multiplicidad de representaciones recibidas y de acuerdo con las reglas categoriales, y no puede entenderse como un sujeto enfrentado a un objeto como si se tratara de dos elementos separables. Sin esta función de unidad no hay objetividad, de modo que ambos polos se co-constituyen mutualmente. En suma, objetividad y subjetividad conforman en Kant una unidad estructural previa a la distinción empírica entre sujeto y objeto.

Pero, al igual que puede verse en el sujeto kantiano el verdadero punto de partida para la constitución de la experiencia -no casualmente el idealismo post-kantiano en sus versiones monistas parte de un yo productor de sí mismo y de la experiencia (Fichte)-, el Dasein posee algunos aspectos que admiten una equiparación con un sujeto, pues abre el campo del sentido como una consciencia y está ligado al pronombre en primera persona. En este último sentido es incluso más sujeto que el sujeto trascendental kantiano, pues es ya la indicación formal de un contenido (Bertorello, 2008, pp. 101 ss.). En suma, al igual que en la filosofía moderna, existe una tensión entre el subjetivismo implícito y la lucha contra el subjetivismo.

Abordaré ahora una tercera ambigüedad, presentada más arriba en relación con la postura anti metafísica de ambos pensadores, y que siguiendo mi hilo interpretativo permite ubicar a ambos pensadores en una misma tradición. Se trata de la filosofía concebida como autoreflexión (en el sentido expuesto más arriba), que da lugar a una interpretación fenomenológica y a una argumentativa. Por un lado, está claro que no hay en Heidegger sujeto cuyas facultades puedan ser estudiadas en algo análogo a la reflexión en el sentido kantiano. Hay, por el contrario, una descripción fenomenológica de las estructuras irrebasables de la facticidad. También puede interpretarse así a Kant, quien realiza una descripción de cómo funcionan las facultades del conocimiento, y sostiene que no se puede explicar por qué poseemos esta estructura racional y no otra - por ejemplo, por qué el entendimiento efectúa la unidad de apercepción a través de este tipo y número de categorías, o por qué el tiempo y el espacio son las únicas formas de nuestra intuición posible (B 145-146).

La pretensión argumentativa es la contracara de esta tarea fenomenológica, algo que se advierte con naturalidad en Kant, quien expresamente desarrolla una Deducción Trascendental, es decir, una justificación de las categorías (su quid juris). En el caso de Heidegger, creo que existe también una "pretensión probatoria” ligada con la reflexión, visible en la crítica a otras posiciones filosóficas y en la justificación constante de la propia posición hermenéutica. La referencia a la tradición filosófica occidental, que tiene facetas “destructivas” pero también constructivas, se encarna en contraposiciones argumentativas explícitas o implícitas.

Finalmente, la auto-reflexión conduce en ambos casos a una paradoja referida a la propia posición, que conduce, como veremos, a una oposición inconciliable. Tanto Kant como 
Heidegger hablan de aquello que, según las limitaciones que ellos mismos exigen para la filosofía, no pueden hablar. En Kant, la concepción del conocimiento como conocimiento empírico deja afuera a la especulación metafísica, remitiendo a los objetos que la razón necesariamente postula al campo del "pensamiento”. Pero los límites críticos deberían restringir el conocimiento de todo lo que, si bien no está "más allá” de lo empírico, se encuentra "más acá”, pues las condiciones del conocimiento también trascienden la experiencia posible. El punto es que para obtener el conocimiento filosófico o trascendental expresado por los enunciados de la propia filosofía crítica es preciso violar las reglas auto-impuestas. Esta violación, y el hecho de que Kant no haya intentado justificar (o “deducir") el propio conocimiento filosófico -sí explicarlo y distinguirlo de otros tipos de conocimiento, como el matemático- se resume en que la filosofía kantiana no es "auto reflexiva”.

Esta paradoja conduce al problema de determinar desde dónde enuncia Kant su posición filosófica. Si lo hace desde una experiencia ya constituida -como debe ser el caso, pues no hay conocimiento antes de la experiencia-, se dificulta el acceso a los elementos que la constituyen. Como he indicado, esta problemática se pone de manifiesto con la “doctrina de la síntesis”. El método de aislar los elementos involucrados en las diversas síntesis se encuentra con el escollo de principio de que estos elementos se encuentran más allá de toda experiencia posible. En tanto elementos que producen la síntesis, no pueden ser fruto de ella. E intentar ubicarse fuera de la experiencia para evitar este escollo implica claramente exceder los límites críticos. En suma, si el propio lugar del filósofo se ubica -o pretende hacerlo- en un terreno que no viole las restricciones de la filosofía crítica, sí lo viola necesariamente el objeto de estudio (las condiciones de la experiencia); y si se pretende abordar este objeto en su propio terreno (un terreno no empírico), ambos, sujeto y objeto de la filosofía crítica, violan las mencionadas restricciones.

En el caso de Heidegger, esta paradoja se agudiza debido a que el punto de partida es la facticidad radical. Las dificultades recién vistas se repiten en tanto se pretende acceder al plano mismo de la constitución del sentido, a la estructura de la pre-comprensión desligada de lo constituido por ella. Con ello se trasciende el hecho de que estamos "siempre ya" en un mundo conformado de tal o cual manera. A esto se le suma una segunda paradoja, determinada por el hecho de que la facticidad radical -el punto de partida de la investigación- le quita validez a toda elaboración teórica que pretenda ir más allá del aquí y ahora. Lo condicionado resulta irrebasable en su "contingencia absoluta”. Las estructuras ontológicas del ser en el mundo no pueden ser asequibles desde el propio ser temporal en el mundo.

Esto lleva a una pregunta de difícil solución: ¿desde dónde habla entonces Heidegger?, o bien, ¿desde qué posición es posible sostener legítimamente las tesis hermenéuticas? Si se lo hace desde perspectiva de un Dasein -la única posibilidad, dado el planteo ontológico fundamental-, sólo se puede acceder a un mundo ya constituido temporalmente, nunca a sus condiciones. Esto fuerza a asumir una perspectiva "meta Dasein" que auto-supera la facticidad radical. En el próximo apartado trataré esto con más detalle.

\section{Finitud y validez universal: Heidegger en el camino de la detrascendentalización}

El análisis de la situación enunciativa muestra una fuerte contraposición entre ambos pensadores e indica un punto en el que Heidegger se aparta claramente de la tradición trascendental. Si hasta el momento me serví de una serie de tensiones propias de la filosofía trascendental para mostrar la común pertenencia de ambos a una tradición, ahora es el momento de abordar una diferencia básica, en la que Lafont ha insistido con razón (cf. por ejemplo 1997, pp. 311 ss). En efecto, si Heidegger hubiese sido un pensador universalista habría reeditado simplemente los dilemas de la tradición trascendental en una nueva jerga, agregando o, mejor, 
enriqueciendo el “idealismo trascendental” con la mediación del lenguaje. Pero su posición es todavía más complicada y comprometida. De hecho, su filosofía trascendental se concibe exclusivamente en base a un "centro” fáctico, finito, temporal. Heidegger no atribuye el carácter de "universal” a lo a priori, profundizando, en cambio, la historicidad radical del Dasein.

El problema que surge es, entonces, el de cómo pueden las condiciones irrebasables y necesarias descubiertas por la analítica estar sometidas al tiempo. Sea cual fuere la correcta interpretación de la temporalidad heideggeriana, tema que excede este trabajo, una de las dimensiones centrales del tiempo es el cambio. Lo que está “sometido" al tiempo necesariamente cambia, pero si las estructuras a priori lo hacen, entonces la propia investigación heideggeriana, como toda posición filosófica, queda restringida a su propia facticidad, que nada tiene para decirle a un lector mínimamente alejado del aquí y ahora en que fuera elaborada.

Hay una manera en la que Heidegger abre la posibilidad de pensar un a priori en un sentido no universal. La facticidad conlleva y recrea cada vez su propio a priori. Así, cada vez que existe una perspectiva fáctica sobre el ser, hay algo “desde siempre”. Heidegger denomina a este "haber desde siempre” arraigado lo fáctico "pretérito perfecto a priori”, o también "perfecto ontológico o trascendental” (SZ, pp. 111 y 111n.). La estructura a priori de esta hermenéutica no debe entenderse como un esquema atemporal que se encuentra disponible para que el Dasein pueda acceder a los otros entes. Por el contrario, esta estructura sólo resulta accesible, posee validez y vigencia, desde la perspectiva del Dasein, pues no es otra cosa que una explicitación de su modo de ser. Lejos de ser atemporal, se trata de algo cada vez previo proyectado desde el propio Dasein.

Un buen ejemplo es la tesis de que el mundo es algo en lo que el Dasein "ya siempre ha estado". ${ }^{13}$ Si bien la noción heideggeriana de "arrojado" en un mundo puede dar la impresión de un alma que habitaba antes otro ámbito, esto es rechazado de plano por la tesis de que no hay un tiempo anterior a este estar arrojado. Precisamente, la expresión que plasma con mayor claridad la noción de perfecto apriórico es la de "siempre ya”, que es una relación sólo en apariencia temporal, pues no alude en realidad a un pasado en el que ciertas condiciones de posibilidad estaban esperando, por así decirlo, a que surgiera lo condicionado. Esta expresión es relativa a la facticidad: todo "siempre ya" lo es de un aquí y ahora. Con esto se evita recargar metafísicamente a la estructura trascendental con el carácter de la universalidad.

Heidegger podría así desarrollar una analítica análoga a la de Kant aunque partiendo de la finitud de la existencia (cosa que, según él, Kant también pretende hacer, cf. GA 3, pp. 20 ss.), sin imponer un fundamento metafísico injustificado. Sin embargo, si bien al nivel de la propia facticidad esta explicación resulta plausible, queda en pie la cuestión de la propia conceptualidad que elabora filosóficamente este "siempre ya". ¿No se cuela en este "siempre" el aspecto rechazado de la universalidad? Nuevamente, en términos generales, ¿qué se puede decir sobre el propio nivel conceptual en el que se desarrolla esta filosofía?, ¿de dónde obtiene su legitimidad la investigación que devela la estructura a priori de la pre-comprensión?

Heidegger señala que las expresiones que explicitan la pre-comprensión fáctica, sacando a la luz las estructuras ontológicas de la comprensión en su sentido auténtico, poseen el carácter de una "indicación formal". Gadamer considera que la empresa heideggeriana en su conjunto posee este carácter, que implica un giro hacia lo histórico y existencial. En efecto, no se trata de expresiones que expresan generalidades al modo de los conceptos, sino que su función es sólo la de indicar aspectos de lo fáctico. Lo importante -como subraya Gadamer- es que el otro debe ver por sí mismo lo indicado (Gadamer, 2002, p. 290). Y Heidegger pone como ejemplo de este tipo de indicación nada menos que el siguiente enunciado: “el Dasein (la vida fáctica) es ser en un mundo” (GA 63, p. 80).

13 SZ, p. 103. 
Guiados por estas consideraciones, podemos ver que para Heidegger la filosofía misma tiene un carácter formal (GA 61, pp. 63-64), y advertimos en esto una distinción e incluso una distancia entre este plano formal y el plano de contenido representado por la vida fáctica. Efectivamente, la propia indicación no debe confundirse con aquello que es indicado: si bien se trata de un metalenguaje adecuado a su objeto -a saber, la facticidad-, no deja por ello de ser un metalenguaje. Como modalidad de la vida fáctica, la investigación posee la peculiaridad de que surge de ella pero retorna sobre la misma para captarla conceptualmente.

A pesar de introducir aspectos formales y, en cierto modo, distanciados del contenido concreto de cada situación fáctica particular, Heidegger insiste en que la legitimidad de la tarea filosófica proviene de la propia facticidad. Así, afirma que para poder definir qué es la filosofía es preciso acceder al contexto vital en el que se la practica (GA 61, pp. 63-64). Teniendo en cuenta que la indicación no es ajena a lo conceptual, podemos decir que funciona como nexo entre la facticidad y los conceptos filosóficos que la elaboran. Heidegger habla precisamente de "significado existencial” (existenzielle Bedeutung), entendiendo "significado" como un momento de la existencia fáctica (GA 59, p. 185). Ciertamente, la facticidad incluye el "haber previo" de la tradición filosófica, pero la tradición es abordada mediante el método "destructivo" que busca descubrir lo originario al nivel de la experiencia donde surgieron los conceptos transmitidos a lo largo de siglos.

En resumidas cuentas, la respuesta heideggeriana a nuestro interrogante sobre la legitimidad de su propia actividad conceptual resulta finalmente unilateral, ya que apunta exclusivamente a la propia facticidad. Si bien Heidegger se muestra reacio a pensar en términos de relativismo o universalismo, y en todo caso pretende alejarse del relativismo propio de la tesis de una pluralidad de concepciones del mundo (GA 63, p. 63), su historicidad radical no puede resultar indemne al reproche natural de relativismo. Pensar exclusivamente con categorías fácticas del acontecer, volviéndose ciego frente a las pretensiones de validez universal presentes en las tesis filosóficas -y ya en el acuerdo comunicativo- lo hacen incurrir en un grave dilema. Se produce de hecho una contradicción entre el contenido de su filosofía y la pretensión de sus enunciados, puesto que la relativización a la historia del ser es presentada como una tesis válida, es decir como poseedora de una validez general no relativizable históricamente (Apel, 1998, pp. 478479).

Esta auto-destrucción ha resultado quizás determinante para el camino dificultoso y lleno de rodeos de la detrascendentalización, es decir la Kehre y el recurso a la poesía. ${ }^{14}$ Como afirma Gadamer, "Heidegger mismo veía que no se puede superar, a partir de una cura del ser ahí (Daseinssorge) profundizada y concretamente viviente, el subjetivismo de la filosofía de la conciencia”. En la época de los años veinte, sin embargo, continúan sus esfuerzos por continuar a Kant subordinando el sujeto trascendental a la propia temporalidad, reiterando con ello otra paradoja de la filosofía kantiana, pues, como afirma Gadamer, “(n)uestra finitud y nuestra historicidad siguen siendo la herencia de la crítica de la metafísica iniciada con Kant” (Gadamer, 2000, p. 165). En todo caso, se trata de una lectura del rechazo crítico de la metafísica que no toma en cuenta el universalismo kantiano y su concepción atemporal de la estructura racional.

En suma, el neokantismo heideggeriano de los años veinte pretende darle un nuevo significado a lo a priori que, más allá de la forma judicativa que pueda adoptar de manera derivada, consiste en una relación ontológica (la estructura hermenéutica de la pre-comprensión hace posible el ser-en-el-mundo) basada en una nueva concepción del tiempo. Pero esta nueva concepción, el perfecto apriórico, elude la necesidad de incluir la nota de la universalidad, no pudiendo escapar a una serie de paradojas conceptuales. Estas paradojas están también presentes

14 Me refiero a este camino como dificultoso pues no deja de ser interpretable como una nueva manera de continuar pensando la apertura del mundo, es decir, la diferencia ontológica, sólo que cambiando el foco de atención (ahora puesto en el ser mismo) y el estilo de expresión. 
en un Kant interpretado como un pensador de la finitud, pero se evitan fácilmente cuando se toma en cuenta que la racionalidad es una estructura atemporal.

Y aún si fuera posible elaborar una filosofía unilateral de la facticidad que reniegue de todo universalismo, centrada en la facticidad y la finitud, quedarían en pie las tensiones propias de la tradición trascendental (eminentemente modernas): los límites al conocimiento y el propio traspaso auto-reflexivo de estos límites, el mundo como siempre ya constituido o como fruto de una constitución activa, la centralidad de un sujeto constituyente o la superación del dualismo metafísico de sujeto-objeto. Es en el marco de estas tensiones que Heidegger elabora una hermenéutica de la facticidad. Aunque más no sea por esto, la tematización de la facticidad radical no resulta una superación unilateral del pensamiento kantiano sino una nueva, y dramática, puesta en escena de la filosofía kantiana.

\section{Referencias}

AGUILAR ALVAREZ BAY, Tatiana (1998), El lenguaje en el primer Heidegger, Fondo de Cultura Económica, México D. F.

APEL, Karl-Otto (1973), Transformation der Philosophie, Suhrkamp, Frankfurt am Main, 2 Bd.

APEL, Karl-Otto (1998), Auseinandersetzungen in Erprobung des transzendentalpragmatischen Ansatzes, Suhrkamp, Frankfurt am Main.

BEISER, Frederick (2002), German Idealism. The Struggle against Subjectivism, Harvard University Press.

BERTORELLO, Adrián (2008), El límite del lenguaje. La filosofía de Heidegger como teoría de la enunciación, Paidós, Buenos Aires.

CRUZ VÉLEZ, Danilo (1970), Filosofía sin supuestos, Sudamericana, Buenos Aires.

GADAMER, Hans-Georg (2000), Reportaje realizado por Fernández, Graciela, en: Fernández, Graciela (Ed.), El otro puede tener razón. Estudios sobre racionalidad en filosofía y ciencia, Ediciones Suárez, Mar del Plata.

GADAMER, Hans-Georg (2002), Los caminos de Heidegger, Herder, Barcelona.

HEIDEGGER, Martin (GA 25), Phänomenologische Interpretation von Kants Kritik der reinen Vernunft (Wintersemester 1927/28), Hrsg.: I. Görland, 1977, 2. Auflage 1987, 3. Auflage 1995, XII, 436 S.

HEIDEGGER, Martin (GA 59), Phänomenologie der Anschauung und des Ausdrucks, Frankfurt am Main, Vittorio Klostermann, 1993.

HEIDEGGER, Martin (GA 61), Phänomenologische Interpretationen zu Aristoteles. Einführung in die phänomenologische Forschung, Frankfurt am Main, Vittorio Klostermann, 1994.

HEIDEGGER, Martin (GA 63), Ontologie. Hermeneutik der Faktizität (Frühe Freiburger Vorlesung Sommersemester 1923), Vittorio Klostermann, Frankfurt am Main.

HEIDEGGER, Martin (SZ), Ser y tiempo. Traducción, prólogo y notas de Jorge Eduardo Rivera C., Editorial Universitaria, Santiago de Chile.

HEIDEGGER, Martin (NB), Interpretaciones fenomenológicas sobre Aristóteles. (Informe Natorp). Edición y traducción de Jesús Adrián Escudero. Trotta, Madrid.

HEIDEGGER, Martin (GA 3), Kant y el problema de la metafísica, Editora Nacional, Madrid.

KANT, Immanuel (2000), Crítica de la razón pura. Prólogo, traducción, notas e índices de Pedro Ribas. Alfaguara, Madrid.

LAFONT, Cristina (1997), Lenguaje y apertura del mundo. El giro lingüístico de la hermenéutica de Heidegger, Alianza, Madrid. 
LAFONT, Cristina (2003), "Verdad y apertura de mundo. El problema de los juicios sintéticos $a$ priori tras el giro lingüístico", en: Azafea. Revista de filosofía 5,2003, pp. 53-74, Ediciones Universidad de Salamanca.

LAFONT, Cristina (2007), "Heidegger and the Synthetic A Priori”, en: Steven Crowell y Jeff Malpas (Eds.), Transcendental Heidegger, Standford University Press, Stanford, California, pp. 104-118.

PERAITA, Carmen Segura (2001), Hermenéutica de la vida humana. En torno al Informe Natorp de Martin Heidegger, Trotta, Madrid.

STRAWSON, Peter (1975), Los límites del sentido: un ensayo sobre la «Crítica de la razón pura» de Kant, Revista de Occidente, Madrid.

VOLPI, Franco (1994), "La existencia como praxis. Las raíces aristotélicas de la terminología de Ser y tiempo»”, en: VATTIMO. G. (Comp.), Hermenéutica y racionalidad, Norma, Buenos Aires, pp. 327-384.

VON HERRMANN, Friedrich-Wilhelm (1997 (1991)), La «segunda mitad» de Ser y Tiempo, Trotta, Madrid. 